\title{
ОБРАЗ КСЕНОМОРФА В АМЕРИКАНСКОМ ФИЛЬМЕ УЖАСОВ: ИДЕОЛОГИЯ АНТРОПОЦЕНТРИЗМА В ИНТЕРПРЕТАЦИИ ЭВОЛЮЦИИ ЖИЗНИ
}

\author{
Маленко Сергей Анатольевич1, \\ olenia@mail.ru \\ Некита Андрей Григорьевич 1 , \\ beresten@mail.ru
}

\begin{abstract}
${ }^{1}$ Новгородский государственный университет имени Ярослава Мудрого, Россия, 173003, г. Великий Новгород, ул. Большая Санкт-Петербургская, 41
\end{abstract}

Маленко Сергей Анатольевич, доктор философских наук, профессор, заведующий кафедрой философии, культурологии и социологии Новгородского государственного университета имени Ярослава Мудрого.

Некита Андрей Григорьевич, доктор философских наук, профессор кафедры теории, истории и философии культуры Новгородского государственного университета имени Ярослава Мудрого.

Актуальность исследования обусловлена тем, что современная массовая культура является примером парадоксальной конкуренции различных типов интерпретации сущности природы и цивилизации. Сегодня в них превалируют популистские и обывательские модели объяснения этих парадоксов, для которых характерны стереотипность, предвзятость и вульгарный антропоцентризм. $B$ то время как исследования современной визуальной культуры призваны актуализировать значение научного подхода в изучении диалектики взаимодействия Ното sapiens с иными формами жизни на планете. Цель: сравнительное семиотическое и психоаналитическое исследование парадоксов современной визуальной культуры, которая все более тяготеет к отказу от естественных природных образов и экранному конструированию искусственных витальных объектов. Методы: феноменологический, семиотический и психоаналитический методы изучения визуальной культуры, позволяющие проанализировать антропоцентристскую символику современной массового общества, его идеологические приоритеты и смысловое содержание. Результаты. Американский фильм ужасов выступает в авангарде процессов, происходящих в современной массовой культуре, и создает особую идеологическую технологию визуализации массовых страхов и фобий по отношению к непознанной окружающей природе планеты. Будучи бессознательными в своем основании, эти эмоциональные состояния имагинируют и объективируют наиболее острые противоречия цивилизации и природы, которые переносятся на дочеловеческие формы жизни. Сложная композиция из атрибутов образов различных живых существ, которые в массовой культуре стереотипно соотносятся с опасностью и злом, сублимируется в визуальных моделях экзоморфных существ. Они становятся общечеловеческими символами зла и смерти и представляют агрессивные способы покорения окружающего мира и культуры. Именно в форме агрессии экзоморфных существ американский фильм ужасов повествует о чрезмерной угрозе для личности и всей природы, исходящей от цивилизованного человечества. Выводы. Показательно, что голливудские кинообразы экзоморфных существ последовательно воспроизводят имагинативные закономерности становления сознания и в силу этого получают особую популярность в массовой культуре. Кроме того, этим художественным образам целенаправленно приписываются сакральные и сверхъестественные качества. Экзоморфы выступают итогом конструктивного симбиоза внешних качеств различных живых существ, их манеры поведения, типа охоты, питания и размножения. В итоге подобные экзоморфные существа являются собирательными образами, в которых концентрируется, с одной стороны, вся мощь природы, а с другой - весь деструктивный потенциал цивилизации как ее искусственного оппонента.

Ключевые слова: Образ ксеноморфа, визуализация, эволюция, идеология антропоцентризма, американский фильм ужасов, массовая культура. 
Один из наиболее одиозных и впечатляющих голливудских образов инопланетного зла был представлен в культовой франшизе о «Чужих» (1979-2017). Восемь серий этой леденящей душу киноэпопеи повествуют об эволюции сюжетной линии, художественных образах и трансформации их идейно-смыслового наполнения: «Чужой» (англ. «Alien», реж. Р. Скотт, «20th Century Foх», США, 1979), «Чужие» (англ. «Aliens», реж. Г. Кэрролл, «Brandywine Productions», США, 1986), «Чужой 3» (англ. «Alien 3», реж. Д. Финчер, «20th Century Fox», США, 1992), «Чужой: Воскрешение» (англ. «Alien Resurrection», реж. Ж.-П. Жёне, США, «20th Century Fox», 1997), «Чужой: Завет» (англ. «Alien: Covenant», реж. Р. Скотт, «20th Century Foх», США, 2017), «Чужой против Хищника» (англ. «Aliens vs. Predator», реж. П.У.С. Андерсон, «20th Century Fох», США, 2004), «Прометей» (англ. «Prometheus», реж. Р. Скотт, «Scott Free Productions», США, 2012), «Чужие против Хищника: Реквием» (англ. «Aliens vs. Predator: Requiem», реж. братья Штраус, «Brandywine Productions», США, 2007). Действительно, созданию и промоушену этого цикла американский ужасный кинематограф на сегодняшний день посвятил уже сорок лет, но до сих пор так и не собирается сворачивать этот более чем удачный коммерческий и, несомненно, идеологический проект. «Создавая одни из самых захватывающих красивых видений в истории коммерческого кино», франшиза оказалась настолько популярной, что затраты на ее производство окупились более чем в три раза, поскольку сборы превысили полтора миллиарда долларов [1, p. 3]. Причем именно первые две серии этого цикла до сих пор остаются голливудскими рекордсменами по полученной в ходе проката прибыли: при бюджете в одиннадцать миллионов «Чужой» (1979) получил в прокате сто пять миллионов долларов. Таким образом, массовый зритель во всем мире одномоментно «проголосовал» за идеи, реализованные в этом шокирующем и новаторском для того времени фильме самым доступным и неоспоримым для социологического и экономического подсчета способом - отдав за них свои деньги.

При этом неподдельный интерес зрительской аудитории связан не только с технологическими новинками и уникальными саспенс-приемами, использованными при съемках и позволяющими «создавать интенсивно "захватывающие" переживания, такие как ужас и идентификация» [2, p. 43]. Значительная часть кассовых сборов обеспечена зрительской уверенностью в непосредственной актуальности сюжета и остроте затронутых франшизой общецивилизационных проблем. В ней во многом впервые как для голливудской, так и для общемировой кинематографической практики были подняты поистине фундаментальные проблемы, относящиеся к визуализации и особенностям идеологического продвижения образов «инаковости», а также специфике их функционирования в современной массовой культуре, которая ужасом маркирует свою территорию и стремится отделиться «от угрожающего животного или звероподобного мира» [3]. Ведь именно на примере образов вымышленных, инопланетных персонажей у специалистов в сфере социальных и гуманитарных наук открывается невиданная ранее возможность проанализировать имагинативные закономерности становления и развития всей современной визуальной культуры, выражающей ведущие тренды деформации антропологических стратегий общества потребления. На эту проблему в свое время обратил внимание и К.Г. Юнг, указывавший, что в современном цивилизованном обществе непременно «возникает ситуация, в которой при всем желании невозможно определить, имеем ли мы дело с иллюзиями, порожденными некоторым первичным восприятием, или наоборот, первичны сами эти фантастические образы, рожденные в сфере бессознательного и захватившие сознание, наполнив его миражами и призраками» [4]. 
Что касается психоанализа имагинаций инопланетного ксеноморфа, то, по убеждению авторов, его необходимо сконцентрировать на изучении целого ряда аспектов: во-первых, проинтерпретировать «ужасную» модель его внешности, во-вторых, соотнести сценарии его экранного поведения со стратегиями внутривидовой и межвидовой борьбы его возможных биотических прототипов, в-третьих, на основании двух предыдущих моментов установить наличие в образе непосредственного идеологического целеполагания, определить его «заказчиков» и дать оценку характеру и формам реализации голливудской концепции инопланетного ужаса в пространстве современной массовой культуры.

Следует отметить, что ужасный образ ксеноморфа во франшизе о «Чужих» не только представляет собой интересную режиссерскую находку Ридли Скотта [1], но и позволяет обнаружить качества, которые в совокупности ассоциируются с типичными деструктивными формами социального зла. При этом они приобретают настолько значительную устойчивость, что превращаются в идеологический стереотип массовой культуры, актуальный для представителей потребительской цивилизации в разных странах на протяжении нескольких поколений. Однако чтобы понять всю масштабность и глубину этого замысла, в первую очередь необходимо внимательно рассмотреть внешность «Чужого». Строение тела этого существа принципиально отличается от Homo sapiens, представители которого в процессе прямохождения приобрели вертикальное расположение туловища, определенную длину конечностей и присущую данному виду относительную пропорциональность всех частей. В отличие от человека голливудский «Чужой» явно не расположен демонстрировать особенности строения своего тела. Наоборот, он тщательно скрывает их, всякий раз оставляя шокированного зрителя один на один с полузабытым попкорном и морфологическими парадоксами своей внешности.

Если сравнить голливудскую визуализацию образа «Чужого» с характерным для христианской традиции образным воплощением Дьявола, то можно увидеть разные модели имагинаций Неизвестного. Несмотря на всю эфемерность этого образа, Дьявол традиционно визуализируется посредством архаических образов существ или черт внешности, которые указывают на явно дохристианский, откровенно «низший» с позиций «высокой» цивилизованности сценарий интерпретации отношений Человека и Бога. Это, как правило, антропоморфное существо, с выраженными чертами языческих божеств, символизирующих свободное тело, максимально раскрывающее свой природный потенциал в веселье и празднике, совершенно естественно чувствующее себя в потоке наслаждений, не ведающее и не страшащееся наказаний за него. В связи с этим В. Северцов справедливо указывает, что «в любую эпоху человеческое бытие подвергается действию иррациональных и по своей сути инфернальных сил, которые подрывают человеческие планы и прерывают позитивное жизнестроительство» [5, с. 91].

Поэтому Дьявол в христианской идеологии просто был «обязан и обречен» стать символом, с одной стороны, тотальной греховности, а с другой - персонифицировать сам путь к ней, указывая на всевозможные способы ее достижения. Это объясняет появление в образе Дьявола явных черт Вакха и Пана, которые походили на любвеобильных козлов. Соответственно и христианский Дьявол получал от них «в наследство» рога, шерсть, бороду, копыта, хвост, характер и особенности поведения. В итоге старые боги, перед которыми христианство было просто бессильно, никуда не исчезали. Им искусственно приписывались агрессивные и деструктивные формы, специфическая идеологическая интерпретация которых на века вперед предопределяла характер их дальнейшего воздействия на обывателя, который является типичным «заложником потребительского комфорта» [6, с. 41]. 
Однако в случае с «Чужим» ситуация явно обстояла несколько иначе. Фенотипическая и поведенческая преемственность Дьявола мифологическим имагинациям языческих миров предоставила этому образу возможность на протяжении более чем двадцати веков по-разному откликаться в душах обывателей, приверженцев различных конфессий, в то время как «Чужой» изначально являлся откровенно общечеловеческим и, несомненно, ксенофобским образом. С другой стороны, визуальный конструкт «Чужого» также не может быть беспочвенным и должен опираться на набор неких отвратительных атрибутов, способных гарантированно пробудить волну древней ненависти в душе и сознании «спящего» зрителя-обывателя.

В итоге выдающиеся интуиции Ханса Рудольфа (Руди) Гигера (Hans Rudolf «Rüdi» Giger, 1940-2014), швейцарского художника, представителя фантастического реализма, некроготики, биомеханики или эротомеханики, и автора образной вселенной «Чужих» позволили сконструировать образы инопланетного зла, опираясь исключительно на человеческие представления о страшном, ужасном и кошмарном. Австрийский художник Эрнст Фукс так охарактеризовал результат работы Гигера: «Люди либо в восторге, либо в ужасе от искусства Гигера. Но никто не знает, как изобразить самые ужасные кошмары так потрясающе красиво» [7]. «Чужой» - это, безусловно, собирательный образ, жуткий и кошмарный конструкт, искусственно составленный из тщательно отобранных черт живых существ, которые на протяжении всей истории коммуникации человека с природой вызывали у него наибольшее отвращение, пренебрежение и страх, который Н. Кэролл называл «художественным» [8]. Стоит согласиться с мнением А. Аксеновой о том, что любой страх уже сам по себе содержит «прорыв в более фундаментальное понимание бытия» [9, с. 60]. $\Phi$. Ницше в свойственной ему манере так охарактеризовал этот парадокс: в подобных телах «помещаются души отягощенных виною людей и что это, на первый взгляд, возмутительно бессмысленное страдание полно высшего смысла и значения перед лицом вечной справедливости - именно есть наказание и покаяние» [10, с. 357].

Поскольку этот образ изначально полиморфен, как и сам Ужас, «Чужого» невозможно привязать к определенному виду насекомых, пресмыкающихся или млекопитающих. Поэтому тщательный, сравнительный фенотипический и анатомический анализ конструкта «Чужого» позволит нам выявить генезис и формы наиболее типичных, глубинных страхов современного человека и меры отчуждения, которое продемонстрировали члены экипажа «Ностромо», - «состояния, определенного Карлом Марксом в разделе "отчужденный труд" его экономических и философских рукописей 1844 года» [11, p. 101]. Итак, центральной частью тела «Чужого», всегда принудительно выпячиваемой в сценах его появления перед людьми, является голова, по форме напоминающая тело мечехвостов из отряда хелицеровых (Chelicerata). Однако верхняя часть головы ксеноморфа спереди напоминает головогрудь насекомых или головоногих моллюсков рода Наутилус (Nautilus), тогда как сзади она похожа на структуру тела ракообразных от головы до хвоста. На черепной коробке не просматриваются глаза, значит, зрение не входит в число его важнейших жизненных коммуникационных функций.

Таким образом, мы делаем вывод о том, что «Чужой» не является прирожденным визионером, а ориентируется в окружающем пространстве иными способами, эволюционный горизонт которых намного ниже рыб, пресмыкающихся и иных высших организмов. В то время как верхняя часть черепной коробки ассоциируется с видом беспозвоночных, нижняя часть недвусмысленно указывает на то, что перед нами жестокий и беспощадный плотоядный хищник. Этот вывод мы делаем, анализируя структуру верхней и нижней челюсти «Чужого», которые в передней части напоминают резцы высших приматов, тогда как оставшаяся часть челюстей представлена острыми клыками. 
Особый интерес вызывает наличие второй пары челюстей, используемых «Чужим» для молниеносной атаки на жертву. Схожую конструкцию челюстного аппарата мы находим у представителей класса лучеперых рыб, отряда угреобразных, семейства муреновых. Использование такого «механизма» позволяет этому виду при атрофии глотательных мышц втаскивать пищу непосредственно в пищевод. «Водная» тема во внешности «Чужого» также связывается с наличием обильных слизей, выделяемых ксеноморфом перед атакой на жертву. Эта конструктивная особенность заимствуется Х.P. Гигером у миксин - одних из самых примитивных, черепных, хордовых эукариотических организмов, родственников пиявок, живущих в Мировом океане. Как и «Чужие», миксины - ночные животные, питающиеся либо падалью, либо рыбами. В том случае, когда жертва еще оказывает сопротивление миксине, она прогрызает ее жабры и удушает ее путем выделения большого количества густой слизи.

Мягкие ткани ксеноморфа тщательно закрыты состоящим из поляризованных органических силикатов экзоскелетом, который не только прячет внутренние органы и мышцы «Чужого», но имитирует живое тело без кожи, на котором отчетливо, можно сказать, даже «порнографично», просматриваются соединительные ткани, связки, мышцы, фасции и кости. При этом, несмотря на наличие экзоскелета, «Чужой» обладает внутренней костной структурой и имеет не менее восьми пар сросшихся пальцев. В отличие от тираннозавра, чью форму тела напоминает «Чужой», передние конечности не являются рудиментарными и развиты достаточно хорошо. В контурах экзоскелета просматриваются соединительные трубки, напоминающие трахею, которые создают дополнительные ощущения нарочитой искусственности данного организма. На задней части спины и локтевых суставах существуют наросты, напоминающие атрофированные крылья. Кроме того, задняя часть туловища заканчивается длинным хвостом с острым саблевидным наконечником, часто используемым для нанесения смертельных ударов жертвам. Внешняя часть хвоста напоминает остов кита.

По поводу внутреннего строения «Чужого» сказать что-либо сложно, поскольку эта информация достаточно несущественна. В то же время у нас есть некоторые вторичные признаки, которые об этом сообщают. Это двуполое существо, имеющее сложный цикл зачатия и рождения. В начале фильма это паразитоидный ксеноморф, откладывающий достаточно крупные кожистые яйца, имеющие удивительную способность сохранять жизнеспособность в самых экстремальных условиях очень длительное время и активирующиеся лишь при наличии определенных внешних обстоятельств, в частности при появлении вблизи яйца организма-носителя. В яйцах развивается личинка лицехват, которая после завершения фазы созревания внезапно и очень быстро нападает на будущего носителя, внедряется через лицо в его организм, подсаживая внутрь эмбрион, обозначающий следующую фазу жизненного цикла «Чужого».

До тех пор, пока эмбрион не начал развиваться внутри тела хозяина, лицехват контролирует все процессы жизнедеятельности носителя, но при установлении самостоятельности эмбриона он немедленно оставляет хозяина. Внешне эта личинка напоминает паукообразное существо отряда хелицеровых (Chelicerata) класса арахнидов (Arachnida), с конечностями, напоминающими человеческую кисть и мощным мышечным хвостом, который осуществляет внешний физический контроль над телом хозяина. Интерес представляет и способ передачи генов, которым обладает ксеноморф: в отличие от высших животных он имеет горизонтальный тип передачи генов, который позволяет ему осуществлять обмен генетической информацией с любым организмом и формировать на этом основании новые виды ксеноморфов. 
В то же время нельзя сказать, что «Чужим» не свойственен вертикальный тип передачи генов, поскольку они двуполы. Комбинация различных типов передачи генетической информации говорит об особом качестве этого организма, нацеленном на замещение собой всех иных видов жизни в процессе колонизации космического пространства. Паразитическое в своей основе и слишком быстрое для человеческого понимания созревание эмбриона в теле хозяина заканчивается его ужасным и в прямом смысле «вероломным» выходом через грудную клетку хозяина/жертвы, что дает этому этапу развития «Чужого» общеизвестное название «грудолом». Внешне грудоломы похожи на червеобразных существ, которые после быстрого прохождения несколько этапов линьки превращаются во взрослых ксеноморфов двух- или трехметрового роста.

Доля ужаса, который вызывает этот образ, значительно усиливается поистине сверхъестественной скоростью его биологического цикла. Схожие чувства вызывают не только странная, явно гибридная физиология, но и демонстрация последствий действия крови ксеноморфа, которая фактически является мощной биокислотой, способной растворить любые известные людям вещества и соединения. Авторы франшизы о «Чужих» очень удачно (как показало победоносное сорокалетнее шествие франшизы по кинотеатрам, душам и поколениям обывателей и экспертов) смонтировали инопланетное тело, умышленно наделив его самыми странными, опасными и пугающими массового обывателя качествами, которые он в принципе смог бы обнаружить в окружающем природном и социокультурном пространстве. Более того, подобный прием и был специально направлен на кинематографическое воспроизведение конструктивистского ужаса, демонстрирующего в общем-то типичную для механистической цивилизации практику бессознательного созидания и последующего идеологического промоушена «теневых» образов. Она заключается в произвольной компоновке «ужасного» образа из фрагментов случайно увиденного, произвольно и некритически заимствованного из СМИ и слухов, подсмотренного на бегу, дофантазированного в кошмарных снах и т. д.

Перечисленные образы «Чужих» по сути характеризуют лишь отдельные фазы развития и, безусловно, обывательского, имагинативного восприятия инопланетного ксеноморфа, что подтверждает действенность распространенного научного стереотипа относительно эволюционного происхождения жизни. Manuela Neuwirth усматривает в этом указание на то, что «абсолютная инаковость таит в себе постчеловеческий потенциал для преодоления границы видов через связь между инопланетянами и животными» [12]. Этапы появления и неоднократного перерождения ксеноморфа «Чужого», понаучному именуемые гемиметаморфозами, соответствуют неполному циклу превращения насекомых и указывают на неоднозначность его эволюции, требующей постоянного пересмотра меры соотнесения качественных и количественных признаков. Подготовленный эксперт обязательно выделит следующие циклы в гемиметаморфозе «Чужого»: яйио (кожистое образование, которое содержит основную генетическую информацию о виде) - триунгулин (паразитический организм, предназначенный для поиска будущего хозяина, в теле которого будет происходить его развитие) - личинка (развивающаяся в теле человека или животного) - имаго (вполне сформировавшаяся особь, которая появляется из личинки). Причем в отличие от насекомых имаго «Чужого» линяет, после чего существенно и очень быстро, просто катастрофически быстро, увеличивает свой размер.

По-видимому, это качество приписывается авторами франшизы ксеноморфу уже не как представителю насекомых, ракообразных, паукообразных и многоножек, а скоpeе, соответствует акту рождения и последующего увеличения в размерах, свойственных для позвоночных. Фактически попадая в благоприятную для размножения биосре- 
ду, в которой присутствуют тела потенциальных хозяев, ксеноморф быстро проходит череду «рождений и смертей», с каждым новым витком своего жизненного цикла только резко увеличивая мышечную массу, размеры тела, сложность повадок и невероятную убойную силу. В то же время имаго «Чужого», несмотря на соответствие его жизненных циклов последовательности гемиметаморфоз насекомых, оказывается, устроено гораздо сложнее их. На это указывает его демонстративное отсутствие потребности в пище и жидкости - ни в одной серии франшизы массового зрителя не посвящали в таинство трофического профиля «Чужого». Зато обывателю за сорок лет удалось сполна насладиться деталями зловещих сеансов самой результативной и смертельной охоты в американском «ужасном» инопланетном кинематографе, которую «Чужой» организовывает из серии в серию. Такая «агрессивная кинодиета» [13, с. 78], несомненно, формирует специфическую направленность идеолого-управленческого посыла, которая подобна всем известному «секрету Полишинеля», ведь любой «фильм ужасов «умышленно» сгущает смыслы, доносимые до массового зрителя сквозь кровь и стоны жертв, добиваясь таким образом максимального «убеждающего» эффекта» [14, с. 1].

В этом смысле идеология ужасной трофики «Чужого» вполне соответствует знаменитой формуле лидера II Интернационала и правого крыла социал-демократии Германии, известного деятеля международного рабочего движения конца XIX - начала $\mathrm{XX}$ века Эдуарда Бернштейна, о которой упоминал в своей работе еще В.Ленин: «Конечная цель - ничто, движение - все» [15, с. 24]. Речь идет том, что в своем стремлении, во что бы то ни стало захватить все доступное жизненное пространство, паразитарный ксеноморф «Чужой» не останавливается ни перед чем, пока не реализует имеющийся у него смертоносный конструктивный набор эволюционных преимуществ.

При этом парадоксально, что сама добыча не является для него привычным в обывательском восприятии источником пищи. Она, скорее всего, предстает символической формой демонстрации доминирующего положения ксеноморфа в любой эволюционной системе. Из серии в серию мы наблюдаем, как члены команды корабля, колонисты, заключенные, врачи, охранники и т. д. спят, питаются и работают. В то время как «Чужой» принципиально и демонстративно находится вне, а точнее «над» этой системой измерений, чем фактически достаточно последовательно и вызывающе демонстрирует антиповседневную и антипотребительскую модель поведения. Что, в глазах обывателя, лишь добавляет его образу таинственности, а, заодно, дополнительно повышает градус саспенса. Несомненно, такое поведение ксеноморфа воспроизводит логику Сверхчеловека, символически объединяя в себе качества различных живых организмов. Но если для Ф. Ницше такое понятие было всего лишь звучной метафорой, то для ужасного голливудского ксеноморфа - это поистине «modus vivendi» (от лат. образ жизни, способ существования).

С другой стороны, ницшеанский Сверхчеловек также проходит определенные метаморфозы: из верблюда его дух превращается во льва, а потом и в ребенка. Логика Сверхчеловека Ницше направлена на осознание необходимости обретения свободы, самовласти и духа-созидателя. В то время как ксеноморф демонстрирует нам гораздо большее, он всем своим жизненным циклом утверждает ужасную последовательность и полное, окончательное торжество жизни над цивилизационным и корпоративизированным, но все равно столь «нищим» духом. И хотя зрителю порою кажется, что ксеноморф всегда предстает одиноким, и когда отправляется на охоту, и когда возвращается с нее, на самом деле идеологическая подоплека его образа совсем иная. Его демонстративное кровожадное одиночество выступает лишь имагинативной сообразностью «цивилизованным» людям, которых он, следуя некоему «инстинкту чести», характерному 
для особи, находящейся на вершине трофической пирамиды, всегда убивает только в рамках ужасного и кровавого поединка.

Не случайно, сценарии единоборства «Чужого» и человека всякий раз напоминают еще и древние инициационные ритуалы, а также «рыцарские турниры», в ходе которых каждому участнику предоставляется возможность не только «выбрать оружие», но и проявить все свои лучшие природные способности. Однако любой ксеноморф всегда представляет лишь одну из особей улья, в котором эти существа живут, размножаются, передавая значимый коллективный опыт. В отличие от человека, которого опасность всегда застает врасплох и ставит лицом к лицу со смертельной угрозой, «Чужой», по сути, является коллективным охотником, тело которого лишь зрительно распадается на отдельные органы и части, функции которых блестяще выполняют отдельные особи.

Например, в серии «Чужой: Воскрешение» (англ. «Alien Resurrection», реж. ЖанПьер Жёне, «20th Century Fox», США, 1997), когда ксеноморфы как будто бы умышленно становятся временными пленниками людей и объектами исследований военных ученых, «заложники» устраивают бойню в лаборатории, специально убивая одну из своих же особей, чтобы с помощью ее крови-кислоты освободиться из заточения. В этой сцене зрителю наглядно продемонстрировано победоносное действие коллективного разума, столь «ужасающее» для разделенного вдоль и поперек мышления «цивилизованного» человека. В итоге инстинктивно сплоченным «Чужим», удается не только обойти эгоистические интересы каждой отдельной человеческой особи, но и разрушить преступный корпоративный замысел ученых, стремившихся использовать потенциал ксеноморфов в военных целях. Развязка эпизода весьма показательна: группа инопланетных организмов, позиционируемая землянами как заведомо «низшая», не просто жестоко, но и с явным удовлетворением, наказывает садистов-ученых, демонстрируя им невиданный потенциал сплоченности, жертвенности, обучаемости, слаженности коллективных действий. Показательно, что на протяжении всей франшизы «Чужие» всегда одерживают кровавую «командную» победу над институциональным и корпоративным эгоизмом, всякий раз доказывая, что если они когда-то и будут «оружием», то только в жизненных интересах своего вида.

Что касается оружия, то все тело ксеноморфа представляет собой идеальную с точки зрения голливудской хоррор-визуальности «машину для убийства»: его экзоскелет устроен таким образом, что все его части либо надежно защищают тело «Чужого» от земных видов оружия, либо выступают как его органические формы, которые в отличие от своих цивилизационных пародий в принципе не знают неудач. Что и говорить, если даже кровь этих существ не только может нанести смертельное увечье человеку, но и полностью парализовать работу сложных автоматизированных систем, поставив под угрозу их работоспособность. Правда, остается открытым вопрос об армейских, гладиаторских повадках «Чужих», которые вполне могут быть сопоставлены со спецназовской бравадой членов поисковой экспедиции как, например, во втором и третьем фильме франшизы «Чужие» (англ. «Aliens», реж. Г. Кэрролл, «Brandywine Productions», США, 1986), «Чужой 3» (англ. «Alien 3», реж. Д. Финчер, «20th Century Fox», США, 1992).

Поскольку ксеноморфы не только изначально не имеют оружия, но и принципиально игнорируют все имеющееся в арсенале людей средства уничтожения, их агрессивные повадки имеют исключительно биотическую детерминацию. Кровавые и неизменно фатальные столкновения человека с «Чужим» в далеком космосе наглядно демонстрируют примитивность стратегии, тактики и самой идеологии «ближнего боя», поскольку даже специально подготовленный «цивилизованный» человек с самым тех- 
нологичным и совершенным оружием в руках оказывается не способным эффективно противостоять существам с таким уровнем видовой сплоченности и потенциалом биотической мощи. Кошмарный характер голливудской визуализации подобного соперничества из серии в серию лишь актуализирует для современного обывателя символический потенциал архаических и инициационных ритуалов, демонстративно придавая им межличностный и персонифицированный характер. И действительно, многие исследователи отмечают, что «для победы над темными силами, инопланетянами <...> героям необходимо выполнить известный ряд действий и соблюсти ряд необходимых условий и правил» $[16$, с. 78$]$.

В голливудском ужасном цикле о «Чужих» все происходит именно так, с той лишь весьма существенной разницей, что «если в архаических мифологиях растительный и животный мир повсеместно становится предметом восхищения и обожествления, то в традициях американских фильмов ужасов бывшие тотемы превращаются в средства развлечения и идеологического контроля за повседневностью масс» $[17$, с. 1]. В результате у «обывателя не возникает самой потребности в поиске дополнительных ресурсов символизации и осмысления собственной повседневности» [18, с. 4].

Показательно, что ужасная голливудская межпоколенческая сага о «Чужих» (как, впрочем, и все предыдущие и последующие фильмы ужасов на эту животрепещущую и болезненную тему) в очередной раз успешно обкатывает в обывательском восприятии сценарий индивидуального противостояния инопланетному злу, что характеризует эти истории как абсолютно индивидуационные и уже потому антицивилизационные и антипотребительские, создавая идеологический подтекст, который «часто охватывает всю культуру» [19, с. 164]. При этом во всех фильмах франшизы особо наглядно демонстрируется, что инициатива применения оружия всегда исходит исключительно от смертельно испуганного человека. А сам Homo sapiens, первоначально абсолютно уверенный в мощи и эффективности имеющегося у него арсенала, в дальнейшем неизменно приходит к трагическому разочарованию. Налицо драма изначально агрессивной по отношению к природе цивилизации, а также идеологический, визуализированный Голливудом многосерийный «гимн» этому хищническому искусственному организму, институциональному конструкту, который неизменно «обнаруживает, что люди являются жертвами репрессивной системы» [20, p. 42] и традиционно воплощает свои претензии на биотическое и социальное господство в форме превентивно развязываемых военных конфликтов как самого надежного и тысячелетиями проверенного коммуникативного сценария.

Исследование выполнено при финансовой поддержке РФФИ в рамках научного проекта № 18-011-00129.

\section{СПИСОК ЛИТЕРАТУРЫ}

1. LoBrutto V. Ridley Scott: A Biography. - Kentucky: University Press of Kentucky, 2019. - 280 p. DOI: $10.2307 / \mathrm{j} . c t v d 7 \mathrm{w} 7 \mathrm{~s} 1$

2. Keogh B., Jayemanne D. «Game Over, Man. Game Over»: Looking at the Alien in Film and Videogames // Arts. - 2018. - V. 7. - Iss. 3. - P. 43. URL: https://doi.org/10.3390/arts7030043 (дата обращения 12.05.2019).

3. Кристева Ю. Силы ужаса. Эссе об отвращении. - СПб.: Алетейя, 2003. - 256 с.

4. Юнг К.Г. Один современный миф: о вещах, наблюдаемых в небе. URL: https://royallib.com/book/yung_karl/odin_sovremenniy_mif.html (дата обращения 12.05.2019).

5. Северцев В. От трагедии к ужасу: аксиологический поворот культуры // Известия Тульского государственного университета. Гуманитарные науки. - 2018. - Вып. 3. - С. 91-99. 
6. Malenko S.A., Nekita A.G. Horror films in unconscious anthropological strategies of biopower // Anthropological Measurements of Philosophical Research. - 2018. - № 13. - P. 41-51. DOI: 10.15802/ampr.v0i13.122984.

7. Биомеханическое искусство. Как художник Ганс Гигер изменил мир научной фантастики, создав «Чужого». URL: https://ru.tsn.ua/nauka_it/biomehanicheskoe-iskusstvo-kak-hudozhnik-gans-giger-izmenilmir-nauchnoy-fantastiki-sozdav-chuzhogo-1351653.html (дата обращения 12.05.2019).

8. Carroll N. The Philosophy of Horror, or Paradoxes of the Heart. - N.Y.: Routledge, 1990. - 256 p.

9. Аксенова А.А. Ужас как «повторное выбрасывание в мир» // Вестник Кемеровского государственного университета. Серия «Гуманитарные и общественные науки». - 2017. - № 1. - С. 60-65.

10. Ницше Ф. Несвоевременные размышления - СПб.: Лениздат, 2014. - 416 с.

11. Conway D. Alien, Alienation, and Alien Nation // Alien and Philosophy: I Infest, Therefore I Am (The Blackwell Philosophy and Pop Culture Series) / Ed. by J. Ewing, K.S. Decker. - Hoboken: WileyBlackwell, 2017. - 240 p. URL: https://doi.org/10.1002/9781119280873.ch10 (дата обращения 12.05.2019).

12. Neuwirth M. «Absolute Alterity»? The Alien Animal, the Human Alien, and the Limits of Posthumanism in Star Trek // European Journal of American studies. - 2018. - № 13-1. URL: https://journals.openedition.org/ejas/12464 (дата обращения 12.05.2019).

13. Жабский М.И., Тарасов К.А. Развлекательное насилие в кинодосуге учащейся молодёжи // Высшее образование в России. - 2018. - Т. 27. - № 4. - С. 76-85.

14. Некита А.Г. Мифология дома в американском фильме ужасов // Ученые записки Новгородского государственного университета имени Ярослава Мудрого. - 2018. - № 3 (15). URL: https://www.novsu.ru/univer/press/eNotes1/i.1086055/?id=1450150 (дата обращения 12.05.2019).

15. Ленин В.И. Марксизм и ревизионизм. URL: http://libelli.ru/works/17-4.htm (дата обращения 12.05.2019).

16. Ионов А. Взаимовлияние популярного кино и городских легенд на примере фильма ужасов // АРТИКУЛЬТ. - 2016. - № 22 (2). - С. 76-84. URL: http://articult.rsuh.ru/articult-22-2-2016/articult-22-22016-ionov.php (дата обращения 12.05.2019).

17. Маленко С. Идеологема «волков и овец»- американские фильмы ужасов в производстве массовой культуры // Ученые записки Новгородского государственного университета имени Ярослава Мудрого. - 2018. - № 6 (18). URL: https://www.novsu.ru/univer/press/eNotes1/i.1086055/?id=1483595 (дата обращения 12.05.2019).

18. Маленко С.А. Мистика дома и мифология оседлости: к онтологии американского фильма ужасов // Ученые записки Новгородского государственного университета имени Ярослава Мудрого. - 2018. № 3 (15). URL: https://www.novsu.ru/univer/press/eNotes1/i.1086055/?id=1450154 (дата обращения 12.05.2019).

19. Кинг С. Пляска смерти. - М.: АСТ, 2003. - 512 с.

20. Minogue K. Alien Powers. The Pure Theory of Ideology. - UK; New York: Routledge, 2017. - 396 p.

Поступила 02.06.2019 г. 
UDC 101.1:316.612:141.333:791.221.9:791.43

\title{
THE IMAGE OF XENOMORPH IN AMERICAN FILM OF HORRORS: THE ANTIROPOCENTRISM IDEOLOGY IN INTERPRETATION OF LIFE EVOLUTION
}

\author{
Sergey A. Malenko1, \\ olenia@mail.ru \\ Andrey G. Nekita 1 , \\ beresten@mail.ru
}

1 Yaroslav-the-Wise Novgorod State University, 41, B. St. Petersburgskaya street, Veliky Novgorod, 173003, Russia

Sergey A. Malenko, Dr. Sc., professor, head of the Department of philosophy, cultural studies and sociology, Yaroslav-the-Wise Novgorod State University.

Andrey G. Nekita, Dr. Sc., professor, Yaroslav-the-Wise Novgorod State University.

Relevance. Modern popular culture is an example of paradoxical competition of various types of interpretation of the essence of nature and civilization. Today, they are dominated by populist and philistine models explaining these paradoxes, which are characterized by stereotype, bias and vulgar anthropocentrism. While the study of modern visual culture is designed to actualize the importance of the scientific approach in studying the dialectic of the interaction of Homo sapiens with other forms of life on the planet. The aim of the research is the comparative semiotic and psychoanalytic study of the paradoxes of modern visual culture, which is increasingly failing to abandon natural images and screen construction of artificial vital objects. Methods. The study is based on the composition of the phenomenological, semiotic and psychoanalytic methods of studying visual culture, which allows analyzing the anthropocentric symbolism of modern mass society, its ideological priorities and semantic content. Results. The American horror film is at the forefront of the processes occurring in modern popular culture, and creates a special ideological technology for visualizing mass fears and phobias in relation to the unknown surrounding nature of the planet. Being unconscious in their basis, these emotional states imaginate and objectify the most acute contradictions of civilization and nature, which are transferred to subhuman forms of life. The complex composition of the attributes of the images of various living beings, which in mass culture stereotypically correlate with danger and evil, is sublimated in visual models of exomorphic creatures. They become universal symbols of evil and death, and collectively represent aggressive ways of conquering the world and culture. It is in the form of aggression of exomorphic creatures that the American horror film tells of excessive threat to the person and all of nature from civilized humanity. Findings. It is indicative that Hollywood film images of exomorphic creatures consistently reproduce imaginative patterns of formation of consciousness and, by virtue of this, are becoming particularly popular in popular culture. In addition, sacred and supernatural qualities are purposefully attributed to these artistic images. Exomorphs are the result of a constructive symbiosis of the external qualities of various living beings, their behaviors, such as hunting, feeding and breeding. As a result, such exomorphic creatures are collective images in which all power of nature is concentrated, on the one hand, and, on the other hand, the entire destructive potential of civilization as its artificial opponent.

Key words: Image of xenomorph, visualization, evolution, ideology of anthropocentrism, American horror film, mass culture.

The reported study was funded by RFBR according to the research project no. 18-011-00129. 


\section{REFERENCES}

1. LoBrutto V. Ridley Scott: a Biography. Kentucky, University Press of Kentucky, 2019. 280 p. DOI: 10.2307/j.ctvd7w7s1

2. Keogh B., Jayemanne D. «Game Over, Man. Game Over»: Looking at the Alien in Film and Videogames. Arts, 2018, vol. 7, Iss. 3, p. 43. Available at: https://doi.org/10.3390/arts7030043 (accessed 12 May 2019).

3. Kristeva Yu. Sily uzhasa. Esse ob otvrashchenii [The forces of horror. Essay on disgust]. St. Petersburg, Alateiya Publ., 2003. 256 p.

4. Yung K.G. Odin sovremenny mif: o veshchakh, nablyudaemykh v nebe [One modern myth: about things observed in the sky]. Available at: https://royallib.com/book/yung_karl/odin_sovremenniy_mif.html (accessed 12 May 2019).

5. Severtsev V. Ot tragedii k uzhasu: aksiologicheskiy povorot kultury [From tragedy to horror: axiological turn of culture]. Izvestiya Tulskogo gosudarstvennogo universiteta. Gumanitarnye nauki, 2018, Iss. 3, pp. 91-99.

6. Malenko S.A., Nekita A.G. Horror films in unconscious anthropological strategies of biopower. Anthropological Measurements of Philosophical Research, 2018, no. 13, pp. 41-51. DOI: 10.15802/ampr.v0i13.122984.

7. Biomekhanicheskoe iskusstvo. Kak khudozhnik Gans Giger izmenil mir nauchnoy fantastiki, sozdav «Chuzhogo» [Biomechanical art. How the artist Hans Giger changed the world of science fiction by creating "Alien"]. Available at: https://ru.tsn.ua/nauka_it/biomehanicheskoe-iskusstvo-kak-hudozhnik-gans-gigerizmenil-mir-nauchnoy-fantastiki-sozdav-chuzhogo-1351653.html (accessed 12 May 2019).

8. Carroll N. The Philosophy of Horror, or Paradoxes of the Heart. N.Y., Routledge, 1990. 256 p.

9. Aksenova A.A. Uzhas kak «povtornoe vybrasyvanie v mir» [The horror as a «re-throwing to the world»]. Vestnik Kemerovskogo gosudarstvennogo universiteta. Seriya «Gumanitarnye i obshchestvennye nauki», 2017, no. 1, pp. 60-65.

10. Nicshe F. Nesvoevremennye razmyshleniya [Untimely reflections]. St. Petersburg, Lenizdat Publ., 2014. 416 p.

11. Conway D. Alien, Alienation, and Alien Nation. Alien and Philosophy: I Infest, Therefore I Am (The Blackwell Philosophy and Pop Culture Series). Eds. J. Ewing, K.S. Decker. Hoboken, Wiley-Blackwell, 2017. 240 p. https://doi.org/10.1002/9781119280873.ch10.

12. Neuwirth M. «Absolute Alterity»? The Alien Animal, the Human Alien, and the Limits of Posthumanism in Star Trek. European Journal of American studies, 2018, no. 13-1. Available at: https://journals.openedition.org/ejas/12464 (accessed: 12.05.2019).

13. Zhabskiy M.I., Tarasov K.A. Razvlekatelnoe nasilie v kinodosuge uchashcheysya molodezhi [Entertaining violence in the cinema-leisure of students]. Vysshee obrazovanie v Rossii, 2018, vol. 27, no. 4, pp. 76-85.

14. Nekita A.G. Mifologiya doma v amerikanskom filme uzhasov [The mythology of the house in American horror movie]. Uchenye zapiski Novgorodskogo gosudarstvennogo universiteta imeni Yaroslava Mudrogo, 2018, no. 3 (15). Available at: https://www.novsu.ru/univer/press/eNotes1/i.1086055/?id=1450150 (accessed 12 May 2019).

15. Lenin V.I. Marksizm i revizionizm [Marxism and revisionism]. Available at: http://libelli.ru/works/17-4.htm (accessed 12.05.2019).

16. Ionov A. Vzaimovliyanie populyarnogo kino i gorodskikh legend na primere filma uzhasov [The interaction of popular cinema and urban legends on the example of a horror film]. ARTIKULT, 2016, no. 22 (2), pp. 76-84. Available at: http://articult.rsuh.ru/articult-22-2-2016/articult-22-2-2016-ionov.php (accessed 12 May 2019).

17. Malenko S. Ideologema «volkov i ovets» - amerikanskie filmy uzhasov v proizvodstve massovoy kultury [The ideology of «wolves and sheep» - American horror films in the production of mass culture]. Uchenye zapiski Novgorodskogo gosudarstvennogo universiteta imeni Yaroslava Mudrogo, 2018, no. 6 (18). Available at: https://www.novsu.ru/univer/press/eNotes1/i.1086055/?id=1483595 (accessed 12 May 2019).

18. Malenko S.A. Mistika doma i mifologiya osedlosti: k ontologii amerikanskogo filma uzhasov [Mysticism at home and the mythology of settled life: to the ontology of the American horror film]. Uchenye zapiski Novgorodskogo gosudarstvennogo universiteta imeni Yaroslava Mudrogo, 2018, no. 3 (15). Available at: https://www.novsu.ru/univer/press/eNotes1/i.1086055/?id=1450154 (accessed 12.05.2019).

19. King S. Plyaska smerti [Dance of death]. Moscow, AST Publ., 2003. 512 p.

20. Minogue K. Alien Powers. The Pure Theory of Ideology. UK and New York, Routledge, 2017. 396 p.

Received: 2 June 2019. 